\title{
Exploratory Analysis on Core Competence Measures of Design Discipline
}

\author{
Zhao Weijun ${ }^{1, a^{*}}$, Wang Tian ${ }^{1, b}$ \\ ${ }^{1}$ School of Packaging Design \& Art, Hunan University of Technology, Zhuzhou,412007, China \\ a zwj706@163.com, b495936371@qq.com
}

Keywords: Design discipline; Core competence; Evaluation system

\begin{abstract}
This paper, based on core competence theory and the questionnaire survey conducted in scholars involved in design researches and education, by means of factor analysis, developed the core competence measures including such first-order measures as academic resources, professional competence and professional performance. Academic resources are made up of four second-order measures: academic reputation, academic team, conditions for talent training \& research and unique value of design discipline. Professional competence includes the following four measures: teaching \& research platform, academic communication and discipline operation ability. Professional performance contains scientific research achievement and talent training. Finally, some implications are considered.
\end{abstract}

\section{Introduction}

As Prahalad and Hamel defined, core competences are the collective learning in the organization, especially how to coordinate diverse production skills and integrate multiple streams of technologies [1]. Therefore, core competences are critical for any organization which wants to fulfill self-development in fierce competitive environments, and they are not only unique capabilities owned by a company, but also a set of integrated organizational resources[2]. In this sense, theory of core competences can also be applied to discipline development and design education.

Accordingly, core competences of design discipline include the following aspects. First, they are valuable, allowing the university to exploit opportunities in development. Second, they are the accumulation and integration of knowledge, resources and capabilities of the discipline. Third, they are the capabilities to give rise to competitive advantage. Fourth, they are the embodiment of academic reputation[3]. Thus, the essence of core competences of design discipline can be defined as followed: these core competences, a kind of academic competitiveness that contributes to sustainable competitive advantage of design discipline, are about harmonizing resources, abilities and processes which are valuable, unique and hard to imitate, and should play crucial role in discipline development. Discipline core competences are conducive to discipline development, talent training and public service, and may exercise a great influence on strategic development and decision-making process in universities. This study, based on core competence theory, adopts exploratory factor analysis (EFA) to assess the reliability and validity of the measures, and establishes the core competence evaluation system of design discipline.

\section{Analysis of Core Competences Evaluation System of Design Discipline}

Academic Resources. Academic resources are valuable assets accumulated for many years. These resources grow as they are applied and shared, reflecting the level of design discipline and the potential of sustainable growth. Academic resources include academic reputation, academic team and conditions for talent training and research, and unique values of the discipline.

Academic reputation is built and determined by contributions made by teachers and students together. The academic reputation has a direct effect on the core competences of a discipline. Academic team includes the academic leader and research team. An excellent academic leader, indispensible to cultivating core competences, not only can enhance the competition position of 
researches in the chosen field, but also can bring great honors to the university. A well-structured research team of a discipline is the guarantee of sustainable development and overall competitive advantage. Above all, the task of design discipline construction is to carry out academic communications and cultivating high-level talented designers and researchers, which differs the university from other art research institutions and art teams[4]. Finally, the unique values of the discipline are difficult for other universities with design discipline to imitate, including resources heterogeneity, research advancement and achievement creativity[5].

Professional Competence. Professional competence is the capability of creating values and acquiring resources[6]. It consists of construction of teaching \& research platform, academic communications and discipline operation ability. Construction of teaching \& research platform mainly concerns about the level of teaching \& research projects and related funds acquisition. The level of teaching \& research projects reflects and measures the overall quality of the discipline development. Meanwhile, the research funds can be used to represent the strength of teaching and research of design discipline and the possibility of successful completion of the projects. The teaching and research funding may come from the granted supporting from related administrative institutions and social financing. Academic communication is about the academic communication of knowledge and creative activities among scholars, including academic creativity and academic activities. The discipline operation ability means the discipline organization, the related institutional establishment and cultural improvement, which is vital to the operation and sustainable growth of design discipline.

Professional Performance. Scientific researches produce academic achievement, while teaching activities create design talents. In the process of long-term teaching practice and scientific researches, achievements and talents are the proofs and demonstration of discipline construction and development. Therefore, the research level of design discipline and the quality and quantity of talents produced have direct effects on the competition position and strength of the discipline. Accordingly, professional performance involves the following two aspects: scientific research achievements and talent cultivation. Scientific research achievements comprise design achievements such as high-level research papers, design awards, and social recognition etc. Talent cultivation concerns about academic achievements made by students, design awards and social reputation of graduates.

\section{Method}

Based on the above analysis, a scholar interview was organized before the original questionnaire was determined. Then, questionnaires were sent to design experts, researchers and doctors for suggestions on improvements. To enhance the face validity of the questionnaire, we modified some expressions and orders of the items. Next, a pre-testing was administrated among 50 master's and doctor's supervisors of design discipline. 35 valid questionnaires were accepted and frequency analysis and factor analysis were made, proving the reliability of the data in general. In the pre-testing process, the items and their expressions were adjusted again based on these respondents' comments and advice. Finally, after modifing some items, we finalized the questionnaire used in this study. The items comprising measures were modified according to related scales. Five-point Likert-type scale anchors were used. Respondents were asked to indicate their level of agreement with each item, where 1 represented "Strongly Disagree” and 5 represented "Strongly Agree”.

To verify the core competence measures of design discipline, questionnaires were e-mailed to the scholars targeted since such people were considered appropriate respondents to provide related information due to their knowledge of design discipline. Of the 300 scholars who received the survey, 200 responded, making the response rate $66.7 \%$. After deletion of 42 unusable questionnaires, 158 valid ones were accepted, making the valid response rate $52.7 \%$. According to the analysis of the demographic characteristics of respondents, the numbers of the scholars aged 30-40, 40-50, 50-60 and over 60 are 27(17.1\%), 65(41.1\%), 48(30.4\%) and 18(11.4\%), respectively. 32(20.2\%) of the respondents are lecturers or assistant researchers, 58(36.7\%) are assistant professors, and 68(43.1\%) are professors or researchers. Additionally, the specialities of these respondents were divided as 
followed: 38(24.1\%) majored in product design, 35(22.2\%) in environmental art design, 30(19.0\%) in visual communication, 31(19.6\%) in fashion design, and 24(15.1\%) in animation \& media design.

\section{Results and Analyses}

Factor Analysis. Reliability analysis is first made, items with CITA(Corrected-item total correlation) of less than 0.3 are eliminated. Principle component analysis(PCA) with Varimax rotation is used. Items with factor loadings of less than 0.5 , a minimum threshold value recommended, or items that do not load any factor or load on different factors are eliminated. Eigenvalues for all factors should be higher than 1. Cronbach's alpha for each construct above 0.7 is considered acceptable.The results show that CITA values of all items are over 0.5, and the Cronbach's alpha values do not increase if the items are deleted[7]. Therefore, all items are kept.

Data analyses show that the KMO values (Kaiser-Meyer-Olkin measure of sampling adequacy) of the constructs are 0.801, 0.703 and 0.758 , respectively. Moreover, the p-values are .000, which shows significant results (less than .05) using Bartlett Test of Sphericity. These results indicate that the data are suitable for factor analysis. Factor analysis for academic resources items yields four factors explaining $72.583 \%$ variance. All the items are kept. The four factors are named as academic reputation, academic team and conditions for talent training and research, and unique values of the discipline. Factor analysis of professional competence items identify three factors explaining $70.146 \%$ of variance, named as construction of teaching \& research platform, academic communications and discipline operation ability. Factor analysis of professional performance items identify two factors explaining $66.290 \%$ of variance, named as scientific research achievements and talent cultivation. All factor loadings of items are above 0.5. All Cronbach's alpha values are above 0.80 , exhibiting acceptable reliability.

According to the above exploratory factor analysis, this paper establishes the core competence evaluation system as shown in Fig.1.

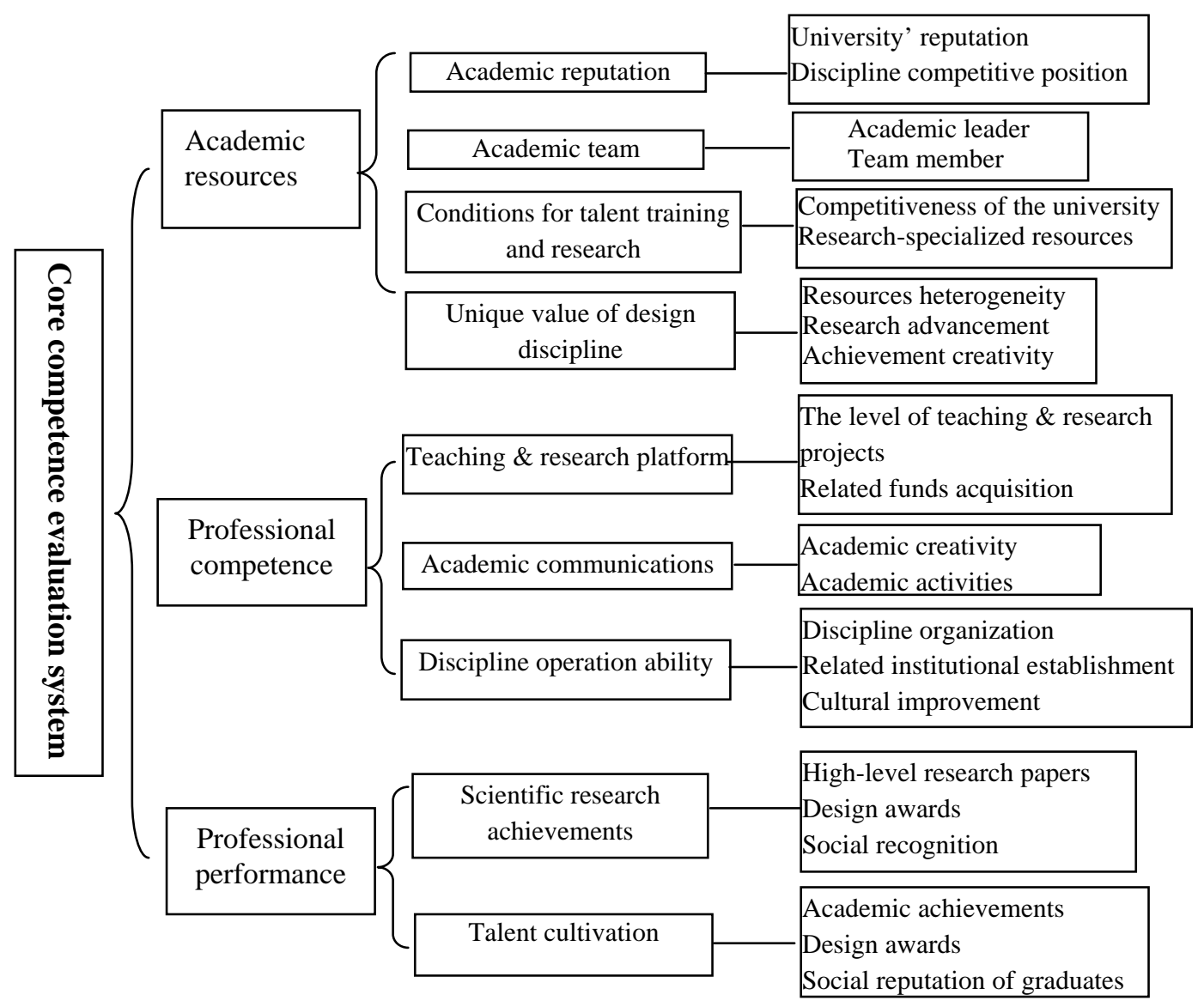

Fig.1 Core Competence Evaluation System of Design Discipline 


\section{Conclusions}

The study of core competence of design discipline is at an early stage in China. There have been some discrete studies, but few studies the application of core competence theory to discipline development, or the cultivation of core competence. Thus, many universities with design discipline haven't made sustainable discipline strategy, which may be harmful to the long-term development of design education. This paper establishes the core competence evaluation system by exploratory factor analysis. The results show that the core competence of design discipline consist of three first-order measures: academic resources, professional competence and professional performance. Academic resources are made up of such four second-order measures as academic reputation, academic team, conditions for talent training \& research and unique value of design discipline. Professional competence includes the following four measures: teaching \& research platform, academic communication and discipline operation ability. Professional performance contains scientific research achievement and talent training.

Although the importance of core competence of design discipline of the university is well accepted, there are barriers to its evaluation system or structures, even some scholars have weak awareness of this problem. The evaluation system may be helpful to cultivating core competence of design discipline.

\section{Acknowledgements}

This work was supported by Planned Project of the Education Science Twelfth-Five Year Research Program of Hunan Province of China (Grand No.:XJK012BJM001).

\section{References}

[1] C.K.Prahalad, C. Hamel, The Core Competence of the Corporation, Harvard Business Review. 68 (1990) 79-91.

[2]S.D. Jian, S.L. Zou, L.J.Yang, et al, Literature Review and outlook on the Competitiveness of universities. 4(2010)20-23

[3]W.J.Zhao, On the Evaluation System of the Core Competence of Arts Subject. 9(2010)126-128

[4]T.Deng, J.X.Mei, W.J.Zhao, et al, Evaluation and Practice of Core Competence of University Art Discipline.5(2011)93-97

[5]Q.H.Zhang, J.L.Fu, L.Wang, Study on the Knowledge Integrationof University Based on the Core Competence. 23(2013)182-186

[6]K.Zhao, Z.W.Wang, On Core Competence Cultivation and Evaluation of Key disciplines of the University. 5(2005)12-16

[7]X.T. Zhang, Advanced Textbook of SPSS Analysis, Beijing, 2007. 